\title{
Therapeutic Possibility of "Semax" for Depression
}

\section{To the Editor:}

September 12, 2007

Along with emerging evidences regarding the role of neurotropic/growth factors in the development of major depression, I attempt to suggest the therapeutic possibility of a revolutionary neuropeptide, "Semax" functioning as neuroregulator, neuromodulator and neuroprotector, in relation with the treatment of major depression.

With regard to the action mechanism of antidepressants, a heptapeptide (Met-Glu-His-PhePro-Gly-Pro) and an analogue of the $\mathrm{N}$-terminal fragment (4-10) of adrenocortico-tropic hormone, "Semax" is an interesting neuropeptide." Emerging evidences suggest that "Semax" may have a potential in the treatment of depression.

It was found that a single application of "Semax" led to a maximal 1.4-fold increase of brain-derived neutropic factor (BDNF) levels as well as 1.6-fold increase of tyrosine kinase $B$ receptor (TrkB) tyrosine phosporylation levels and a 3-fold and a 2-fold increase of BDNF and TrkB mRNA levels, respectively, in the rat hippocampus. ${ }^{2}$ This finding is intriguing since a number of preclinical and clinical studies have demonstrated that reduced BDNF is directly involved in the pathophysiology of depression, in particular in the hippocampus, and that its restoration may underlie the therapeutic efficacy of antidepressant treatment. ${ }^{3}$ Activation of TrkB signaling is an another important trigger for the behavioral effects that is typically observed by antidepressants. ${ }^{4}$

The proposition that "Semax" may be indirectly related to hippocampal neurogenesis reflecting its direct effect on BDNF, also suggests that "Semax" may potentially have antidepressant effect since hippocampal neurogenesis is clearly implicated in the pathogenesis of depres- sion and treatment effect of antidepressants. ${ }^{5}$

In an animal study, "Semax" was effective in enhancing the activity of dopaminergic and serotonergic neurotransmission system, which is most widely accepted principal action mechanism of antidepressants. "Semax" has already proven its efficacy in the treatment of cognitive impairment due to neuronal insults in clinical studies, ${ }^{7}$ indicating its potential effectiveness for elderly depressed patients who are frequently accompanied with comorbid neurological conditions such as stroke and cerebral infarction.

Simultaneous administration of "Semax" and D-amphetamine resulted in a more profound increase in the locomotor activity of mice, pointing its modulation effect on dopaminergic systems that is involved in the formation of the psychostimulant effect. $^{8}$

The potential psychostimulant effect of "Semax" has been implicated in the treatment of depression since it was proven that depressed patients benefit from augmentation of psychostimulants in clinical studies. The combination of an antidepressant (ie, citalopram) and a psychostimulant (ie, methylphenidate) has shown to accelerate and enhance the antidepressant response in depressed patients in a placebo-controlled clinical trials. ${ }^{9}$

"Semax" may exert a key role in the treatment of depression considering its interaction with the pivotal neurotrophic factors and neurotransmitters. Therefore, further research on the precise roles of "Semax" for treating depression warrant more attention to extend our understanding about depression in the future.

Sincerely,

Chi-Un Pae, MD 


\title{
Communique
}

\section{REFERENCES}

1. Agapova TY, Agniullin YV, Shadrina MI, et al. Neurotrophin gene expression in rat brain under the action of Semax, an analogue of ACTH 4-10. Neurosci Lett. 2007:417:201-205.

2. Dolotov OV, Karpenko EA, inozemtseva LS, et al. Semax, an analog of ACTH(4-10) with cognitive effects, regulates BDNF and trkB expression in the rat hippocampus. Brain Res. 2006;1117:54-60.

3. Groves J0. Is it time to reassess the BDNF hypothesis of depression? Mol Psychiatry. In press

4. Saarelainen T, Hendolin P, Lucas $G$, et al. Activation of the TrkB neurotrophin receptor is induced by antidepressant drugs and is required for antidepressant-induced behavioral effects. J Neurosci. 2003:23:349-357.

5. Paizanis E, Hamon M, Lanfumey L. Hippocampal neurogenesis, depressive disorders, and antidepressant therapy. Neural Plast. 2007:73754.

6. Eremin KO, Kudrin VS, Grivennikov IA, Miasoedov NF, Rayevsky KS. Effects of Semax on dopaminergic and serotoninergic systems of the brain. DokI Biol Sci. 2004;394:1-3.

7. Gusev El, Skvortsova VI, Chukanova El. Semax in prevention of disease progress and development of exacerbations in patients with cerebrovascular insufficiency. [Russian]. Zh Nevrol Psikhiatr im S S Korsakova. 2005;105:35-40.

8. Eremin K0, Saransaari P, Oja S, Raevskii KS. Semax potentiates effects of D-amphetamine on the level of extracellular dopamine in the Sprague-Dawley rat striatum and on the locomotor activity of C57BL/6 mice [Russian]. Eksp Klin Farmakol. 2004;67:8-11.

9. Lavretsky H, Park S. Siddarth P. Kumar A, Reynolds CF 3rd. Methylphenidate-enhanced antidepressant response to citalopram in the elderly: a double-blind, placebo-controlled pilot trial. Am J Geriatr Psychiatry. 2006;14:181-185.
Dr. Pae is associate professor in the Department of Psychiatry, Kangnam St. Mary's Hospital, at the Catholic University of Korea College of Medicine in Seoul, South Korea, and psychopharmacology fellow in the Department of Psychiatry and Behavioral Sciences at Duke University Medical Center in Durham, North Carolina.

Dr. Pae has received research support from AstraZeneca Korea, Eli Lilly and Company Korea, GlaxoSmithKline, GlaxoSmithKline Korea, Janssen Pharmaceuticals Korea, the Korean Institute of Science and Technology Evaluation and. Planning, the Korean Research Foundation, Otsuka Korea, and Wyeth Korea; and has received honoraria and is on the speaker's bureaus of AstraZeneca Korea, Eli Lilly and Company Korea, GlaxoSmithKline Korea, Janssen Pharmaceuticals Korea, Lundbeck Korea, and Otsuka Korea.

Please send letters to the editor to: CNS Spectrums, c/o Eric Hollander, MD, 333 Hudson St., 7th Floor, New York, NY 10013; E-mail: vi@mblcommunications.com.

\section{Now Available Online at www.cnsspectrums.com} CME-ACCREDITED SUPPLEMENT

\author{
by Paul E. Keck, Jr., MD, Mark A. Frye, MD, and Michael E. Thase, MD \\ To request a published supplement, pleasee-mail ks@mblcommunications.com \\ Supported by an educational grant from AstraZeneca.
}

